\title{
¿Una "Nueva Época" del Partido Comunista Mexicano? Rupturas y continuidades en el comienzo de la década de los sesenta
}

\author{
A "New Epoch" of the Mexican Communist Party? Ruptures \\ and continuities in the early $60^{\prime} \mathrm{s}$
}

Jaime Ortega Reyna

Universidad Autónoma Metropolitana-Xochimilco, México

Recibido: 02/08/2017

Aceptado: 12/10/2017

Resumen: El artículo explora los cambios y renovaciones de la concepción política de los comunistas mexicanos. Dichos cambios son ubicados en los primeros años sesenta. Su punto central es la ruptura con la "ideología de la Revolución Mexicana". Todo ello se aborda a partir de una publicación hasta ahora no estudiada, la revista Nueva Época. Se exploran dimensiones como la producción teórica, la influencia de la revolución cubana y la centralidad de la democracia como concepción política. Todo ello tiene como finalidad explicar los orígenes de la transformación del Partido Comunista Mexicano en los años setenta. El proceso de renovación concluiría en 1982 con su disolución.

Palabras claves: Revolución mexicana, comunismo, Partido Comunista Mexicano, Nueva Época

Abstract: The article explores the changes and renewals of the political conception of Mexican communists. These changes are in the early 1960s. Its central point is the rupture with the "ideology of the Mexican Revolution." All this is explored from 
a publication so far not studied: the magazine Nueva Época. It explores dimensions such as theoretical production, the influence of the Cuban revolution and the centrality of democracy as a political conception. All this is intended to explain the origins of the transformation of the Mexican communist party in the 1970s. The process of renewal would conclude in 1982 with its dissolution.

Keywords: Mexican revolution, communism, Mexican Communist Party, Nueva Época

\section{Introducción}

En febrero de 1961 se lanzaba al estrecho espacio público mexicano una publicación más del Partido Comunista Mexicano (PCM): la revista Nueva Época ${ }^{1}$. Sostendremos en este texto que, a pesar de las limitaciones que ella expresa en sus contenidos, se trata de un espacio que mostraba algunas de las transformaciones más importantes, tanto en la cuestión estrictamente nacional, como en la mirada regional. Tras nueve años de existencia dejaría de aparecer en su número 31, en el año 1970. Esa década será crucial para el partido, pues apuntalará su proceso de reforma interna. En la publicación se expresarían, por un lado, los principales nudos problemáticos de una organización política que buscaba superar sus errores anteriores y, por el otro, formular una nueva concepción política acorde con la realidad mexicana de la época. Al mismo tiempo, era cada vez más clara la distancia con el "gran hermano" soviético, con el cual se marcarían diferencias en distintos momentos, siendo la invasión a Checoslovaquia un evento clave, calificado en su momento por el comunismo mexicano como "un gravísimo error". ${ }^{2}$

El PCM era la organización política más antigua del país, nacida al calor de la Revolución Mexicana había sufrido un “atropellado amanecer”3 marcado por la

\footnotetext{
${ }^{1}$ Es en el Archivo del Centro de Estudios del Movimiento Obrero y Socialista (CEMOS) en donde hemos consultado la totalidad de los números de la revista. Agradecemos a quienes laboran en el Archivo por las facilidades.

2 TIRADO, Tirado, "El problema checoslovaco y la posición de principio del PCM", Nueva Época, Año VII, No. 19, enero de 1969, p. 53.

3 CONDES LARA, Enrique, Atropellado amanecer: el comunismo en tiempos de la revolución mexicana, México, BUAP, 2015.
} 
decisiva influencia de la ideología de dicha revolución, consagrada con fuerza a partir de la fundación del moderno Estado en 1917, es decir, sólo dos años antes del nacimiento del que sería el primer partido comunista de la región. Respecto a lo que sucedería después de la desaparición de la publicación, es bien sabido que el PCM sufrió un proceso de reforma interno en los años ochenta que lo llevó a su disolución y unificación con otras fuerzas en 1982. También se ha destacado que en los años setenta predominó un giro democrático alcanzado bajo la dirección comunista de Arnoldo Martínez Verdugo - que toma el cargo de Secretario General en 1960-, en gran parte posible por la apropiación productiva de las obras de Antonio Gramsci. La revista que estudiaremos ahora se encuentra en medio de esos dos procesos, por un lado, el de deslindarse definitivamente de la ideología oficial del Estado mexicano y por la otra, que fue parte del camino que se siguió en el proceso de reforma en los años ochenta. En este trabajo mostraremos los primeros pasos de aquellos cambios, en los que a decir de Concheiro se muestra cómo en el comunismo mexicano se observaba la oscilación entre "el atraso y la emancipación, entre la marginalidad y la vanguardia”. 4

A nivel de la cristalización de esas sinergias renovadoras es común señalar la aparición, en los años ochenta, de la revista El Machete -dirigida por el hoy célebre antropólogo Roger Bartra- como un gran influjo renovador del discurso comunista. Aquella revista no fue la única que muestra las transformaciones de dicho discurso, pues su antecedente inmediato, la revista Historia y Sociedad5 expresa un momento muy relevante de la reforma al interno del partido. Esta última publicación fundada por Enrique Semo en 1965, contó con el apoyo de la embajada soviética, pero también de la dirección partidaria, con dos periodos de existencia; el segundo de ellos - que corre en los años setenta- es el que visibiliza más los cambios al interior del mundo comunista. Previamente Nueva Época fue vehículo de expresión de las tensiones y contradicciones del PCM, en proceso de

4 CONCHEIRO, Elvira, "Los comunistas mexicanos: entre la marginalidad y la vanguarida”, Elvira CONCHEIRO; Horacio CRESPO; Massimo MODONESI (Comp.), El comunismo: otras miradas desde América Latina, México, CEIICH, 2007, p. 530.

5 ILLADES, Carlos, La inteligencia rebelde, México, Océano, 2012, p. 52. 
tránsito a una forma renovada de entender la política, la democracia y también el espacio de la teoría.

Nuestra hipótesis es que la revista Nueva Época fue vehículo de las tensiones y contradicciones que se comenzarían a labrar en los años sesenta en el PCM, en donde el influjo de la revolución cubana, la perspectiva de ser una opción electoral y, sobre todo, la regeneración ideológica del comunismo mexicano, se expresaron de manera compleja, es decir, no lineal. Desarrollaremos nuestra hipótesis en tres argumentos: a) la pobreza inicial de la teoría y sus tímidos esfuerzos por superar dicha situación; b) la dimensión conflictiva de la presencia de Cuba y; c) la construcción conceptual político-ideológica, alejada de la ideología de la revolución mexicana.

En este texto nos limitaremos a examinar los contenidos que se encuentran en los primeros años de vida de la revista. Sólo en el caso de la influencia de la Revolución Cubana haremos una excepción, pues la discusión alcanza su tope cuando la obra del francés Regis Debray irrumpe en el escenario, a propósito de la estrategia revolucionaria. En cambio, en los otros casos nos limitaremos al periodo 1961-1965. Debido a que en este periodo se desplegaron opciones de construcción política como el Movimiento de Liberación Nacional (MLN), el Frente Electoral del Pueblo (FEP) y la Central Campesina Independiente (CCI), expresiones novedosas de una izquierda que pretendía abrirse caminos tras décadas de proscripción, represión y derrota. En este periodo queda también comprendida la campaña electoral del comunista Ramón Danzós Palomino. En segundo lugar, porque 1965 es el año de fundación de la ya mencionada revista Historia y Sociedad, que se presenta como una revista exclusivamente teórica y, por tanto, el espacio donde dicho registro se desarrollará de manera autónoma.

Así, Nueva Época viene a significar el primer intento de trazar líneas de demarcación al interior del partido, la más significativa de ellas fue la ruptura con la ideología de la revolución mexicana. Aunque significativa, la intención de construir un espacio de debate teórico fue débil; en cambio, los nudos que implicaba la ideología de la revolución mexicana fueron finalmente desatados. De 
ahí la importancia de la revista en el contexto del despliegue del comunismo mexicano.

\section{La pobreza de la teoría}

La revista Nueva Época se encuentra atrapada entre dos situaciones. La primera, es que se trata de la sucesora de la revista Teoría, editada por el Comité Central del PCM y, la segunda, es que se trata del antecedente inmediato de Historia y Sociedad. Claramente es posible valorar positivamente nuestro objeto de estudio frente a la pobreza conceptual que significaba la revista Teoría. ${ }^{6}$ Esta última se anunciaba como una revista teórica, sin embargo, mostraba límites muy evidentes, en tanto que discutía más los combates del partido en los movimientos de la época y, prácticamente, ninguna elaboración de talante teórico. Es por ello que en el número cuarto de la revista Nueva Época se incluyó una reseña aparecida en la Revista Internacional -un órgano del Movimiento Comunista Internacional- escrita por el comunista español Baudelio Sánchez, en donde se elogia la aparición de la revista y señala que ella "supone un paso adelante en comparación con sus antecesores, las revistas Teoría y Liberación”.7

Del otro lado Nueva Época muestra sus límites en lo teórico muy pronto, pues Historia y Sociedad buscó, con sus propias contradicciones, renovar el discurso marxista, tanto en términos de su amplitud regional - pretendía y lo logró, ser una revista latinoamericanista-, como en la inclusión de temas y autores. A la postre se convertirá en la revista teórica más importante producida por el comunismo mexicano, en donde se debatió sobre el modo de producción asiático, sobre el lugar de la producción artística en el capitalismo, además, se entabló diálogo con las corrientes anticoloniales y, también, con el psicoanálisis. Por sus páginas se conocieron teóricos como Louis Althusser, historiadores como Manfred Kossok, latinoamericanistas como René Zavaleta, Bolívar Echeverría o Agustín

\footnotetext{
${ }^{6}$ Es en Centro de Estudios del Movimiento Obrero y Socialista (CEMOS) en donde he podido consultar algunos de los números de Teoría, una revista ausente en la historiografía sobre el comunismo en México.

7 SÁNCHEZ, Baudelio, "Un portavoz de los comunistas mexicanos”, Nueva Época, Año 1, no. 4, octubre de 1962, p.70.
} 
Cueva, sólo por mencionar algunos nombres relevantes. La diferencia entre ambas publicaciones es la independencia que guardó Historia y Sociedad con respecto al partido, promovida en gran medida por Enrique Semo como director y apoyada por Arnoldo Martínez Verdugo. Nueva Época no era una revista que gozara de cierta independencia del partido, sino una expresión directa de la política que tuvo espacios de discusión más allá de lo inmediato.

En el caso que nos convoca podemos decir que algunos leves indicios nos hablan de un intento de darle un espacio a la reflexión teórica, entendida ésta como una dimensión reflexiva de más largo aliento. Aunque limitada, se encuentra presente. Es decir, la revista es expresión de las batallas de una época y de un proceso de renovación que no logra cristalizar de manera cabal. A pesar de ello, nos parece importante señalar algunas de sus posibilidades para equilibrar mejor sus alcances y límites.

En su número primero ya se encuentra un primer asomo de lo que decimos: una exposición de la dialéctica a cargo de un autor soviético de nombre Rozhin, quien expone directamente la temática sin más mediaciones. No lo hace sobre la base del "materialismo dialéctico" tan común en aquella época de manuales, sino a través de la exposición de la obra de Lenin, particularmente, de la exposición que éste hace de los aportes de la Ciencia de la Lógica de Hegel. Rozhin hace una exposición del punto de vista de Lenin con el lenguaje clásico: unidad de los contrarios, la dialéctica como método de conocimiento, la "naturaleza contradictoria de la cosa”. Aquí nos encontramos en la órbita tradicional de cómo entendían la "lógica dialéctica" los autores soviéticos y también los comunistas mexicanos, siendo lo más relevante que no se adjudican las categorías a algún manual tradicional soviético, sino que se recurre a Hegel por la vía de Lenin. ${ }^{8}$ Ello resulta importante, pues muestra cómo nombres como el del filósofo alemán eran tratados de manera positiva, a partir de las indicaciones dadas por el dirigente ruso. Como es sabido, Lenin indicó que la lectura del filósofo idealista era un

8 ROZHIN, V.P, “En torno a los elementos de la Dialéctica”, Nueva Época, Año 1, No. 1, febrero de 1961, pp. 7-10. 
requisito necesario para la comprensión de Marx. Además de ello, la versión "dialéctica" presentada por Lenin no pasaba por la construcción de una gran narración cosmológica sobre la materia, sino que asentaba el planteamiento hegeliano en la historia y la sociedad.

El número segundo de la revista no entrega un texto propiamente teórico. Sin embargo, si presenta algo que es una novedad para el discurso comunista (y que en la posterior revista Historia y Sociedad será predominante): un intento de re inscripción de las coordenadas históricas del país. Es quizá este elemento el más productivo en la época: el de volver el debate histórico, también teórico, en donde las coordenadas disciplinares no aparecen claramente definidas y es posible operar con los materiales entregados de distintas formas. La historia no es, entonces, una disposición clara de agentes establecidos, sino la disputa de sujetos sociales a través de coordenadas variadas, sin privilegio de algún sujeto sobre otro. Esto que argumentamos se repite en varias ocasiones, la primera de ellas se hace de la mano de un texto de A. B. Belenki, un autor soviético que exploraba las causas de la intervención francesa en México (1861-1867).9

Más allá de los argumentos puntuales, existen dos motivos por los cuales considero que textos como éste abrían nuevas perspectivas. En primer lugar, porque buscaban construir un relato histórico de acuerdo con alguna indicación de Marx, quien rechazó aquella intervención; en segundo lugar, porque buscaban colocar la idea de que el gobierno progresista de Juárez pretendía ser minado por fuerzas locales conservadoras aliadas a la reacción internacional. Esos dos momentos de construcción histórica permitían hablar de una posición teórica: la necesidad de recurrir a Marx, así fuese por breves indicaciones o referencias más bien dispersas, amén de la persistencia de la categoría de imperialismo que, como es sabido, se construyó después del clásico alemán. El esfuerzo en la revista es por darle sentido a todo ello, incluso forzando algunas categorías como la ya

9 BELENKI, A.B, “Objetivos y carácter de la intervención extranjera de 1861-1867”, Nueva Época, año 1, No. 2, abril de 1962, pp. 22-29. 
mencionada imperialismo, unificando en una sola operación los problemas nacionales con la teoría de pretensión universal.

Algo parecido encontraremos en el número 9 de diciembre de 1963, en el que se publica el texto del historiador soviético Alperovich sobre la participación de las masas populares en la Guerra de Independencia. Aprovechando los materiales historiográficos dados por José María Luis Mora, Lucas Alamán, Luis Chávez Orozco, por mencionar sólo algunos, el historiador soviético teje la historia de las insurrecciones que condujeron a la liberación del "yugo español" y el nacimiento de la nación mexicana. Centrándose en los procesos de insurrección, se señala la importancia de personajes como Hidalgo y Morelos. escribe:

Contundente, como suelen ser los textos de tipo historiográfico de la época,

Expresando los intereses de los campesinos y de otras capas de la población trabajadora, así como de la parte más avanzada de la naciente burguesía mexicana, con estado de ánimo radical, Hidalgo y Morelos veían las tareas de la revolución no sólo en la emancipación del yugo español, sino también en la realización de profundas transformaciones en el régimen económico, social y político de México. ${ }^{10}$

Si bien estos dos últimos textos no tocan temas exclusivamente teóricos, habría que recordar que para la teoría marxista de la época, según la formulación de Palmiro Togliatti, la "historia [es] la substancia de la política". Para la comprensión de la época se puede decir que sin historia no hay teoría. La reconstrucción que hacen los historiadores soviéticos de la historia de México delinea las formas interpretativas, asigna lugares y roles, clasifica a sectores de la sociedad según su "papel histórico". Hoy estas construcciones pueden aparecer como carentes o faltas de información, sin embargo, eran entendidas como combates políticos, que dotaban de sentido y pretendían traducir las teorizaciones de Marx a una realidad específica y concreta.

El número tercero trae una indicación que resulta digna de resaltar: la reseña a cargo de A. Villanueva, seudónimo de Enrique Semo, de una recopilación

10 ALPEROVICH M.S, "El papel de las masas populares en la Guerra por la Independencia de México”, NuevaÉpoca, Año II, No. 9, diciembre de 1963, p. 66. 
de textos inéditos de Engels, aparecida en Moscú en el año de 1960. Se trata de una recopilación que se hace de trabajos periodísticos de Engels aparecidos de The Labour Standart que versan sobre cuestiones económicas variadas. Resaltamos su inclusión porque la teoría expresada en la reseña es plenamente acorde con la versión canonizada del "leninismo" y que fue compartida por personajes tan heterogéneos como Stalin, Zinoviev y Trotsky: el capitalismo analizado por Marx corresponde al de la época de la "libre competencia", en tanto que la época posterior es la del dominio de los monopolios y del capital financiero. Villanueva le pone incluso fecha al nacimiento del imperialismo. Categórico, expresa en su recensión: "Corría el año 1881. El capitalismo entraba en una nueva fase: la del imperialismo. La libre concurrencia moría, cediendo el lugar al dominio de los monopolios."11 Resulta significativo pensar que aún en los sesenta se pesaba en términos teóricos como se había decretado en los años veinte la herencia "leninista", es decir, aquella que limitaba la comprensión de la obra de Marx a un periodo histórico, en tanto que se asumía la interpretación de la obra de Lenin tal cual la signaron los primeros dirigentes soviéticos.

Es Semo, quizá, el principal teórico del comunismo en la época y lo será todavía un par de décadas más con una importante producción teórica e historiográfica no lo suficientemente valorada. Economista de formación, en este periodo podemos decir que sigue la línea dura de la interpretación económica. Sin embargo, se permite algún tipo de intervención distinta a ésta. En el número 11 de 1965 presenta el primer texto que reflexiona sobre el lugar de los intelectuales comunistas dentro del partido. El texto resulta sumamente sugerente, pues Semo traza una división tras los sucesos de 1958 con la emergencia del movimiento ferrocarrilero en el seno de la intelectualidad "democrática". Según su apreciación, a partir de ese momento se dan "los inicios, penosos, lentos, pero seguros, de la conformación de una intelectualidad proletaria, de una intelectualidad comunista". ${ }^{12}$ Citando a Gramsci, Semo procede a delimitar que el intelectual no es

${ }^{11}$ VILLANUEVA, A, “10 artículos inéditos de Engels”, Nueva Época, Año 1, No. 3, agosto de 1962, p. 61.

12 VILLANUEVA, A. "Las tareas de los intelectuales comunistas", Nueva Época, Año III, No. 11, mayo-junio de 1965, p. 28. 
el teórico, ni el universitario, sino aquel que ocupa en la sociedad un lugar en el que organice el sentido de los actos prácticos. La inclusión de Gramsci en estas reflexiones como algo más que un mártir comunista es ya un indicativo de los esfuerzos teóricos que florecerán con fuerza a mediados de los años setenta, en donde el autor italiano será un referente para delinear el nuevo trayecto de la política comunista en clave democrática. ${ }^{13}$

Así, con las apreciaciones de Gramsci y la teoría de la exterioridad de la ideología socialista sobre el movimiento obrero, Semo anota los dilemas y problemas de la intelectualidad comunista: su origen de clase, su papel relativamente más estable en el entramado económico, las contradicciones con el partido "representante de la clase obrera", entre otros. Apuesta Semo a que el intelectual no sucumba ante las mieles del poder y de la aspiración a los cargos en la administración, a que defiendan la cultura nacional que se ve asediada por un supuesto cosmopolitismo (que no sería otra cosa que una forma del imperialismo cultural) y, en general, a que luche para "derrotar el pesimismo" en el que pueden encontrase al estar en una posición intermedia. Situación que es la de ser comunistas y, al mismo tiempo, provenir de una clase que no es la proletaria. Más allá de cierta simpleza de algunos de los argumentos, no habría que dejar de pasar que esta es la primera intervención que reconoce a los intelectuales como un sector necesario para el comunismo, independiente y en proceso tenso con los esfuerzos partidarios, así como es importante señalar que la apropiación teórica de Gramsci es novedosa en el medio comunista, aunque su persistencia como dirigente histórico sacrificado por el fascismo era algo más presente.

Cabe mencionar también el número séptimo en el que podemos nuevamente incluir algún contenido con densidad teórica significativa. ${ }^{14}$ Se trata de la traducción de dos textos recién publicados en Moscú y hasta ese momento inéditos. Bajo el rótulo "Lenin y el movimiento de liberación de las colonias" se presentan a

\footnotetext{
13 CONCHEIRO, Elvira, "Gramsci en América Latina”, Massimo MODONESI (coord.), Horizontes gramscianos, México, FCPyS-UNAM, 2013, p. 266.

14 "Lenin y el movimiento de liberación en las colonias", Nueva Época, Año II, No. 7, abril-mayo de 1963, pp. 17-21.
} 
los comunistas mexicanos una carta del dirigente ruso a Máximo Gorki y otra a Inés Armand. La primera está fechada en 1911 y la segunda en 1917, el centro de los fragmentos que se presentan en la conflictividad de los pueblos coloniales (en el primer caso China, en el segundo una reflexión más general) en el plano de la lucha revolucionaria mundial. Se trata de la última inclusión de cierta relevancia en el periodo que centraremos nuestro estudio.

Quizá sólo como dato final convenga fechar la única inclusión de un texto del teórico fundamental del socialismo. Hacia finales de 1969, en el número 19, se publica un texto hasta entonces inédito de Marx, la respuesta al Chicago Tribune, motivo que nos hace reflexionar sobre las formas de circulación del autor reconocido como el más importante para esta tradición política. ${ }^{15} \mathrm{Al}$ igual que otros partidos de la región el PCM dependía, en gran medida, de las publicaciones soviéticas para acceder a las obras de Marx. La editorial del partido solía reproducir las traducciones de la Editorial Progreso que, en América Latina, también se replicaban en las editoriales de Argentina (Cártago, encargadas de la publicación de Lenin) o de Uruguay (Pueblos Unidos, centrada en Marx-Engels). En México, ese lugar lo ocupó Ediciones de Cultura Popular. La publicación que señalamos ahora es de las pocas en las que se adelanta algún inédito de Marx, sólo en la revista Historia y Sociedad de 1967 con motivo del centenario de El Capital de Marx se hizo algo equivalente.

\section{La revolución cubana irrumpe en la escena}

El "huracán" que supuso la revolución cubana conmovió las certezas que se expresaban en las declaraciones del denominado "movimiento comunista internacional". Nadie salió indemne de la reconfiguración política que ella supuso. Más temprano que tarde los partidos de la región tuvieron que enfrentarse a rupturas y escisiones desencadenadas a partir de ese suceso. La dirigencia comunista mexicana mantuvo también sus puntos de tensión con el acontecimiento cubano.

15 MARX, Carlos, "Entrevista al corresponsal el Chicago Tribune”, Nueva Época, Año VII, No. 19, enero de 1969, pp. 19-28. 
En esta parte del texto haremos una revisión sucinta de esos puntos problemáticos y tensos. La revista Nueva Época fue un punto de confluencia de dicho proceso, en donde la dirigencia comunista mexicana asumía un claro apoyo de Cuba, interpretaba esa revolución en un sentido y se confrontaba con otras posibilidades que ella también ofrecía. Ya desde la editorial del primer número se mencionaba que la aparición de la revista también respondía en gran medida al fenómeno que acontecía a pocos kilómetros de las costas mexicanas. En ese primer número se incluye un artículo sin firma que denunciaba la exclusión de Cuba ante la OEA, señalando los rasgos autoritarios y anti comunistas de aquella decisión. Estas zonas discursivas eran claramente declarativas, producto de un apoyo genuino de la única revolución socialista del continente. Existieron otros puntos, sin embargo, más complejos. Haremos mención de algunos de ellos.

De esa zona discursiva en donde el comunismo se identificaba con la revolución cubana hay que destacar, además de las denuncias contra el imperialismo, el sentido más profundo que ella dejaba hacia el resto de los países de América Latina: la posibilidad de que el anti imperialismo fuera también una vía o camino a seguir para conseguir la ansiada construcción del socialismo. Esto es conceptualmente muy importante y tomó un nombre muy claro a partir de los años sesenta: la liberación nacional. En el número 5-6 de la revista se exponen las Tesis rumbo al XIV Congreso, en donde el énfasis se coloca en la poderosa emergencia de los movimientos de liberación nacional como un camino posible para la instauración del socialismo en la región. Vale la pena citar una de esas Tesis partidarias:

Uno de los hechos más relevantes de la actual situación internacional es el ascenso del movimiento de liberación en América Latina. La lucha de los pueblos latinoamericanos adquiere mayor extensión y profundidad y la clase obrera desempeña en esta lucha un papel cada vez más decisivo. El desarrollo y consolidación de la revolución cubana; el fracaso de la invasión de los mercenarios entrenados y armados por el imperialismo norteamericano; la frustración de los propósitos de invasión directa, y la ayuda que los países del campo socialista prestan al desarrollo económico y cultural de Cuba, inspiran a los pueblos latinoamericanos. ${ }^{16}$

16 "Los comunistas y la situación política actual", Nueva Época, Año II, No. 5-6, enero-marzo de 1963, p. 6. 
La incorporación de la tesis de la liberación nacional resulta crucial en países en donde la nación se encuentra asediada por las fuerzas del imperialismo. La irrupción del "huracán caribeño" permitió dimensionar de mejor forma esta tesis que ya había sido discutida desde tiempo atrás. Si bien ello podría parecer menor, sostengo que el comunismo mexicano adquirió plena conciencia del significado de la dualidad nación-anti imperialismo a partir de la Revolución Cubana en el contexto de un horizonte de articulación política más radical, ya que señaló la necesidad de readecuar el horizonte estratégico inmediato. Sin embargo, esta adhesión no impidió que se marcaran líneas con aquella experiencia. Si en términos de estrategia, la liberación nacional se aceptó como un objetivo preciso para la conquista del socialismo, fue en la táctica o el "método" de lucha en donde se marcaron serias discrepancias con la popularización de la experiencia cubana nombrada comúnmente como "foquismo".

Queremos entonces enfocarnos en un texto muy posterior, pero que, sin embargo, guarda relación con lo que hemos dicho. Se trata del texto que escribe el dirigente comunista Gerardo Unzueta, en donde analiza el texto de Regis Debray. Recordemos que la irrupción del planteamiento de Debray puede ser leída de distintas maneras. La edición del libro del escritor francés fue hecha por Casa de las Américas y elogiada por Fidel Castro, con lo cual ganaba cierta resonancia entre el mundo de la "nueva" izquierda. Los ejemplos de la lucha armada que daba Debray se basaban en las situaciones de Venezuela y Guatemala, además de las de Cuba. Si la de Cuba era una revolución exitosa, los modelos de Venezuela y Guatemala pronto se descubrirían como frustrados, al grado que los venezolanos escribieron alguna violenta carta contra Fidel Castro y los guatemaltecos fueron dispersados. Estos procesos fueron analizados autocríticamente por Debray en los dos tomos su obra La crítica de las armas. Sin embargo, en esta época Debray definía al castrismo como la emergencia de una nueva estrategia revolucionaria, que no tenía nada que ver con el formalismo y burocratismo partidario. Debray, alumno de Louis Althusser, cimbró las interpretaciones teóricas sobre la estrategia revolucionaria, volviéndose una especie de "vocero" de la estrategia cubana. Era de 
esperarse que los partidos comunistas de la región no lo recibieran con los brazos abiertos.

Las críticas y contra críticas no se hicieron esperar. Si Roque Dalton, por entonces exiliado en La Habana, hacía una magistral defensa del francés en su ¿Revolución en la revolución? y La crítica de derecha, los cuadros comunistas de la región se lanzaban contra él. Los comunistas argentinos, por ejemplo, en un tono muy común, dijeron que el francés "menosprecia en absoluto el papel de la clase obrera $^{17}$ " y, por tanto, el de su partido; en tanto que los mexicanos no se quedaron atrás, aunque por razones distintas. Así, Nueva Época fue el espacio en donde la Revolución Cubana fue bien recibida en su horizonte estratégico (la necesidad de la liberación nacional), pero no su supuesta táctica (el foquismo).

Las críticas que Unzueta lanzaba eran claras: el aventurerismo y el desafío a las organizaciones comunistas regionales no debe ser tolerado. El recorrido de Unzueta apuesta a desvirtuar a Debray a partir de una interpretación del acontecimiento cubano como un desprendimiento de la lógica mundial de confrontación entre el capitalismo y el socialismo. Aunque Unzueta apunta coincidencias en las valoraciones de Debray, considera que sus conclusiones son erradas y deben ser planteadas, so pena de, por ejemplo, justificar posiciones como las de Mao que salen del esquema binario de la confrontación mundial. La interpretación del mexicano sobre el proceso cubano es absolutamente distinta de la del francés. Dice Unzueta, por ejemplo, que la revolución caribeña demostró la necesidad de "un núcleo marxista-leninista unido", ${ }^{18}$ es decir, un partido clásico.

Así, escribe Unzueta: "Deja en pie un nuevo mito: el del guerrillerismo a ultranza como sustituto de la gran variedad de formas de luchas y sus combinaciones, que es una de las conquistas teóricas más importantes de la táctica marxista-leninista". ${ }^{19}$ Como es bien sabido, los comunistas del mundo seguían en

${ }_{17}$ GHIOLDI, Rodolfo, No puede haber revolución en la revolución, Buenos Aires, Anteo, 1967, p.12. 18 UNZUETA, Gerardo, “Un fraude a la revolución (respuesta a Regis Debray”, Nueva Época, Año V, No 17, agosto de 1967, p. 35.

19 UNZUETA, Gerado, op. cit, p. 36. 
esta época centrados en el desarrollo del "partido de la clase obrera" como "vanguardia" que adaptaba variados métodos de lucha. No es casual que algunos números atrás, en el número 8 de junio-julio de 1963, se presenta el texto de Ernesto "Che" Guevara referente a la construcción del partido marxista-leninista ${ }^{20}$ como un ejemplo de lectura del acontecimiento cubano en términos de la táctica.

Los comunistas mexicanos aceptaban de la irrupción cubana la estrategia de la liberación nacional, sin embargo, también señalaban diferencias con respecto al "modelo" cubano expresado por Debray. Para ello, cosa curiosa, preferían al Che, no de Santa Clara, sino al Che ministro y militante de hierro, forjador del nuevo instrumento de dirección de la sociedad. Cuba era entonces, no un motivo de radicalización sin más, como sucedió con otras experiencias, sino más bien la que permitía integrar al horizonte cotidiano la noción de la liberación nacional en su relación con la lucha con el socialismo.

\section{El adiós a la revolución mexicana: la Nueva Época del comunismo en México}

La historia de los partidos comunistas de la región está atravesada por una doble dimensión, lo que el marxista boliviano René Zavaleta denomina "la lógica del mundo" y la "lógica del lugar". Esta doble dimensión se encuentra siempre en tensión. Por un lado, los partidos comunistas respondían a condiciones locales y específicas y, por el otro, eran deudores de una concepción universalista de la historia. Del lado de la "lógica del mundo" el comunismo tuvo su referente en la Unión Soviética y en una construcción narrativa de tipo teleológico. En cambio, a nivel local tenían que abandonar esa narración y asumir las dimensiones conflictivas que se presentaban en cada coyuntura específica. Aquí sostenemos que la revista Nueva Época si bien respondió a la "lógica del mundo", también permitió la construcción de nuevos horizontes a partir de la "lógica del lugar".

20 GUEVARA, Ernesto, “La clase obrera cubana forja su partido”, Nueva Época, Año II, No. 8, juniojulio de 1963, pp.13-22. 
Podemos preguntar qué significaba este cambio radical del rostro en las condiciones del comunismo mexicano en los años sesenta. Estos años representan el recambio en la política del PCM, con respecto a la revolución mexicana, así como un afianzamiento de una concepción democrática como la vía más adecuada para avanzar hacia el socialismo. Existen dos datos iniciales que pueden confirmar esta apreciación. En primer lugar, la convergencia de dos procesos que son coetáneos y responden a lógicas distintas. De un lado se encuentra la formación del Movimiento Liberación Nacional (MLN), producto del influjo de la revolución cubana y de la iniciativa del ex presidente Lázaro Cárdenas. El segundo es la formación de la Central Campesina Independiente (CCI), que tendrá la emergencia de los cuadros campesinos en la época electoral.

El registro dejado en la revista Nueva Época de ambos procesos es fundamental, pues desatarán las discusiones que transitan de una concepción política a otra novedosa. En el número primero Gerardo Unzueta establece la posición del partido con respecto al MLN, más allá de la interpretación que hacia el comunismo de la formación de dicha organización (y las contradicciones de algunas de sus disposiciones estatutarias), resulta crucial captar una transformación que queda consignada en el texto: "El movimiento así, no se circunscribe a las demandas de una revolución democrático-burguesas del viejo tipo, sino avanza hasta colocarse en las posiciones del movimiento nacional liberador de nuestra época, uniendo el contenido anti imperialista y anti feudal las demandas democráticas de las masas, de la clase obrera y los campesinos". ${ }^{21}$ Este punto resulta crucial pues se da un paso más allá de la interpretación de México como un país feudal que requiere una revolución democrático-burguesa en la que participe la "burguesía nacional". En otras palabras, la revolución a la que aspiraban los comunistas dejó de ser interpretada como esa revolución "anti feudal”. Ese importante paso tiene efectos políticos muy específicos, pues el sujeto de la demanda democrática no es la burguesía, sino "las masas", compuestas por campesinos y obreros.

${ }^{21}$ UNZUETA, Gerardo, "El MNL, una perspectiva para las luchas del pueblo", Nueva Época, Año I, No. 1, febrero de 1961, p. 17. 
Esta posición no era la única que se daba en el partido, ella contrasta con la que expresa Edelmiro Maldonado quien en el informe al pleno del Comité Central expone una posición en tensión con la anterior, así queda registrada en el número segundo de Nueva Época:

Los hechos prueban que esta capa de la gran burguesía no obstante los importantes lazos económicos y políticos que tiene con el capital extranjero, mantiene ciertas contradicciones con el imperialismo yanqui y sus lacayos, contradicciones que se manifiestan en cuestiones de política internacional, en los problemas del comercio exterior, en el capitalismo de estado. ${ }^{22}$

Las posiciones, contradictorias, apenas son una pequeña prueba de lo que vendría adelante con motivo del congreso partidario de 1963. Estas posiciones que quedan tenuemente asentadas en sus aspectos contradictorios, y de las cuales hemos tomado ejemplos, estallarán plenamente con el proyecto de programa que se comenzará a discutir con motivo del XIV Congreso que será, sin duda, el más importante para el cambio de perspectiva política. Nos interesa destacar aquí el tránsito hacia esta otra propuesta política en donde la Revolución Mexicana será cuestionada en tanto que forma ideológica fundamental de toda transformación y en donde la democracia entendida como la conquista de demandas por partes de sectores obreros y campesinos adquirirá centralidad. Ya desde la propuesta de programa, presentada en el número 3 de Nueva Época, se anuncian algunas caracterizaciones nuevas, que exponemos sintéticamente. La primera es el destino de la reforma agraria y, la segunda, versa sobre la necesidad de superar la propia Revolución Mexicana.

Sobre el primer tema, el proyecto de programa expone claramente: "Después de 45 años de reforma agraria burguesa, los campesinos mexicanos no han visto realizado el lema "Tierra y libertad" levantado por Emiliano Zapata en 1911; los campesinos han recibido muy poca tierra y no disfrutan de ninguna libertad". 23 Este incumplimiento será crucial para el giro que tendrá el partido en la década de los sesenta, que a decir de un historiador de la época, concurre entre un discurso

${ }^{22}$ MALDONADO, Edelmiro, "El camino ultraizquierdista conduce a la derecha", Nueva Época, Año I, No. 2, abril de 1962, p. 13 .

23 "Programa del Partido Comunista Mexicano (Proyecto)", Nueva Época, Año I, No 3, agosto de 1962, p. 19. 
centrado en la clase obrera, pero que se encuentra asentado en las masas campesinas. Juan de la Fuente en su estudio sobre el papel de la Central Cardenista Independiente insiste en esta dimensión que el comunismo tiene que enfrentar: la mayor parte de las movilizaciones de la época no vienen de los sindicatos y la clase obrera, sobre quienes pesa tanto el corporativismo como las derrotas del año 1958, sino del mundo campesino. El PCM tiene que adaptarse a esta situación y no lo hará mal. ${ }^{24}$

El número 5 de Nueva Época es una expresión de esta emergencia del movimiento campesino. No sólo porque en su portada se ilustra la imagen de Rubén Jaramillo, dirigente campesino asesinado recientemente, quien es la pieza clave - como ha mostrado Tanalís Padilla - de la articulación entre el movimiento campesino zapatista y las luchas de la izquierda moderna, ${ }^{25}$ sino porque, además, en dicho número se recoge un conjunto de documentos de la CCI. Asimismo, al publicarse los documentos de llamado a su conformación y el programa final que tendrá la CCI, se presenta un saludo que el PCM dirige a la recién constituida organización campesina. Destacamos aspectos que son fundamentales: 1) en términos simbólicos es importante destacar que el PCM reconoce que el campesinado de la CCI está alejado de la oficial CNC y es el heredero de Emiliano Zapata, Pancho Villa y Rubén Jaramillo; 2) en términos internacionales señala que la organización independiente del campesinado es también una consecuencia de eventos regionales: "La revolución cubana es el aliento y la esperanza de la revolución latinoamericana en marcha"26; 3) y más importante, el PCM define el objetivo de la lucha campesina de la siguiente forma: "La central campesina independiente está llamada a ser, necesariamente, el baluarte de las grandes masas en su lucha por la reforma agraria radical...” ${ }^{27}$ Este último elemento, según el ya

24 DE LA FUENTE, Juan, Contra viento y marea: la pertinaz historia del movimiento campesino y las izquierdas, México, UACH, 2016.

25 "el jaramillismo provee un vínculo conceptual entre los movimientos raizados en la Revolución y aquellos que surgirían a lo largo de la segunda mitad del siglo XX" PADILLA, Tanalís, Después de Zapata, México, AKAL, 2016, p. 20.

26 "Los comunistas y la situación política actual”, Nueva Época, Año II, No. 5-6, enero-marzo de 1963, p. 64.

27 Ídem. 
citado estudio de De la Fuente, es crucial para entender la emergencia del movimiento campesino en los años sesenta que vino a ser la bisagra entre las movilizaciones obreras de los años cincuenta y las de los años setenta.

El PCM se nutrió del componente campesino en tal medida que fue uno de los líderes de ese movimiento quien fue presentado como candidato presidencial por el Frente Electoral del Pueblo (FEP). Esa doble experiencia (campesina y electoral) acercó al PCM a nuevos contingentes sociales con los que no tenía contacto y, sobre todo, permitió visibilizar algunas de las contradicciones más grandes del régimen: el debilitamiento de la reforma agraria, la debilidad del movimiento obrero independiente y, por supuesto, lo que será la clave del régimen postrevolucionario: la ausencia de democracia.

Todo ello obligó a repensar y romper con las coordenadas políticoideológicas heredadas por la Revolución Mexicana, así como los aliados tácticos y estratégicos. También, por supuesto, se cuestionó la concepción general de la política, que será lo que analizaremos ahora. En el número 9 de 1963 de Nueva Época, se reproduce el discurso de Ramón Danzós Palomino, titulado significativamente "Contra la imposición y el Fraude". ${ }^{28}$ Ahí se exponen los principales problemas que el proceso electoral visibilizó para el partido: la democracia y el régimen autoritario, junto al imperialismo como una presencia constante, son los más importantes. Este elemento no puede dejar de ser soslayado: la movilización electoral de las organizaciones populares y los vínculos que el PCM exploraba, abría posibilidades nuevas, pero, al mismo tiempo, recargaba la interpretación de la coyuntura política en su eslabón más importante: la democratización del régimen político.

Señalamos anteriormente el segundo gran tema presente en la discusión en general y en el espacio de la revista: el de la Revolución Mexicana como un hecho histórico e ideológico que tendría que ser superado. Cuestión que parece sencilla pensar el día de hoy, pero que en ese momento era una verdadera ruptura con el

28 DANZÓS, Ramón, “Contra la imposición y el fraude electoral (discurso)" en Nueva Época, Año II, No. 9-10, diciembre de 1963, pp. 90-103. 
esquema de evaluación de la situación social, así como un rompimiento con una poderosa ideología de Estado. El marxista José Revueltas, a lo largo de su obra política, trató de desentrañar los secretos de esta forma de dominación y, aunque por fuera del PCM en ese momento, no cabe duda de que compartía algunas preocupaciones con las búsquedas partidarias que él resumiría como una “enajenación histórica”. ${ }^{29}$ Todo esto se expresa en el proyecto de programa de la siguiente manera: "La nueva revolución que México necesita ha de ser una revolución democrática, de liberación nacional, una revolución antiimperialista enfilada también hacia la liquidación de los residuos feudales". $3^{\circ}$ Esta resolución, que a la postre veremos se impondrá como el eje articulador, sólo adquiere sentido cuando se sigue el debate que se suscitó en Nueva Época. Aquel XIV Congreso abrió toda una serie de discusiones en torno al camino y contenido de la "nueva" revolución que los comunistas observan como una obligación impulsar.

La revista es útil, pues permite seguir algunas de las discusiones más importantes al seno del partido. Así, en el número 4 un texto de Valentín Campa titulado "El desarrollo económico de México y su caracterización”, que firma desde la cárcel, caracteriza el régimen surgido de la revolución como aquel que transformó la estructura económica del país de semifeudal a una dependiente industrial. Con este cambio de concepción se establecen dos marcas; la primera de ellas es trazar una línea de demarcación con respecto a otras agrupaciones de izquierda:

Lombardo Toledano intencionalmente repite la afirmación de que México sigue siendo semicolonial, para demostrar que la burguesía nativa en general es progresiva y escamotear el carácter reaccionario del fuerte sector de la gran burguesía fusionado con el gobierno. Por otro lado, los grupo de Rousset y José Revueltas, eluden el carácter dependiente del país y de hecho lo niegan, considerando a toda la burguesía homogénea y reaccionaria. ${ }^{1}$

La segunda es que se alude, por fin, a la ruptura con el régimen de la Revolución Mexicana, pues se pone en el centro de la determinación del régimen

29 REVUELTAS, José, Ensayo sobre un proletariado sin cabeza, México, Era, 1987, p. 75.

30 "Programa del Partido Comunista Mexicano (Proyecto)", Nueva Época, Año I, agosto de 1962, No. 3, p. 21.

${ }^{31}$ CAMPA, Valentín, "El desarrollo económico de México y su caracterización”, Nueva Época, Año 1, No 4, octubre de 1962, p. 29. 
que, es la gran burguesía la que gobierna con una política abiertamente reaccionaria y subordinada al imperialismo: "Hay grandes burgueses que son agentes del imperialismo, pero lo que caracteriza el conjunto de ella es su tendencia a asociarse con el imperialismo yanqui y a la conciliación con ese imperialismo". ${ }^{2}$ Cuando el debate gira en torno a la caracterización del capitalismo mexicano, lo que se discute es la concepción de aquello que se nombró Revolución Mexicana, es decir, sus alcances y sus límites.

El texto de Valentín Campa suscitó debates al interior de la revista. El fondo de la cuestión era para los comunistas de la época un debate que hoy se antoja añejo, pero que en el momento era crucial: definir al capitalismo mexicano como "industrial-agrario" o "agrario-industrial". Nueva Época es el espacio donde aparece la sección "Tribuna del XIV Congreso"; en su número 7 de abril-mayo de 1963, tanto Gerardo Unzueta, como Enrique Semo - firmando con su seudónimo-, insistirán en el punto central: la caracterización de la economía mexicana. Además de ello, se publican algunas de las intervenciones de los militantes y células que hacen matices, críticas o correcciones a la propuesta de programa. Para fines expositivos nos centraremos, primero, en las intervenciones de los intelectuales comunistas.

Gerardo Unzueta, en un intento por sistematizar la polémica levantada por el programa del partido, evalúa desde "la ley del valor", las condiciones poblacionales, tanto de la producción agraria, como de la industrial. Unzueta considera varios elementos: la utilización estadística del Producto Nacional Bruto y de la Renta Nacional; el peso específico de la población utilizada en la producción agrícola e industrial y, principalmente, el carácter de la industrialización: "El nivel de desarrollo de la industria: predominio muy considerable de la industria ligera y extractiva y casi ningún desarrollo de la industria pesada”. $33 \mathrm{Su}$ conclusión es terminante: no hay tránsito al predominio industrial sobre lo agrario, ello debido al

${ }^{22}$ CAMPA, Valentín, op. cit, p. 40.

33 UNZUETA, Gerardo, “Acerca de la caracterización económica de México”, Nueva Época, Año II, No. 7, abril-mayo de 1963, p.42. 
lento avance las fuerzas productivas, a su vez, derivado por la presencia, tanto de "restos feudales", como de la presencia del imperialismo.

Por su parte, Enrique Semo también realiza una caracterización al adherirse a la idea de una multiplicidad de formas de producción articuladas formalmente: "En nuestro país es posible encontrar los siguientes modos de producción: ciertos restos de la comunidad primitiva, el sistema feudal en descomposición, la pequeña producción que está muy difundida y el modo capitalista de producción, que es el dominante". ${ }^{34}$ Semo realiza un análisis de los distintos niveles de estas formas de producción, destaca, por un lado, la ausencia de más estudios sobre la pequeña propiedad que cuenta con cierto apoyo del Estado y, por el otro, el lugar del campo, particularmente, la discusión sobre la existencia de una "burguesía agraria" o una clase de "terratenientes capitalistas", caracterizados por arrendar la tierra. Semo se coloca en una postura desde la que atacar al "terrateniente capitalista" no es equivalente a luchar contra la burguesía agraria. "Las expropiaciones de todos los terratenientes feudales o burgueses deber ser una de las demandas del programa del PCM (...) Este lema no tiene carácter socialista ni aspira a abolir el sistema capitalista de producción". 35 Todas estas discusiones tendrán resolución tanto en el Informe al XIV Congreso (19 al 23 de diciembre de 1963) publicado en el número 10 de Nueva Época, como en la publicación del programa, aparecido en el número 12.

Junto a la caracterización del capitalismo mexicano, es conveniente señalar que se le acompaña de una valoración crítica de la situación política. Como se estilaba en el método marxista de la época, la economía se presentaba primero, después se exponía la política y, por último, las contradicciones sociales. Así, tras la valoración de la "estructura", se aludía a la "super estructura" a través de la evaluación crítica del régimen político. En su repaso, eran los gobiernos de los años cuarenta los que no sólo habrían llevado al país por el camino de su integración dependiente con el imperialismo, sino que, además, habrían impedido el pleno

34 VILLANUEVA, A, "El método marxista en el estudio del desarrollo económico de México", Nueva Época, Año II, No. 7, abril-mayo de 1963, p 53.

35 VILLANUEVA, A. op. cit, p.55. 
desarrollo de la democracia. El comunismo mexicano, al percatarse de ello, pone énfasis en el conjunto de sus tareas en la democratización del régimen. Algunas de las demandas que se harán populares en 1968 con el movimiento estudiantil (libertad a los presos políticos, la lucha por derogar el delito de "disolución social") son ejes de la política comunista desde el momento previo al XIV Congreso. En las Tesis elaboradas previas a éste, se escribe:

Una de las tareas primordiales de nuestro Partido consiste en luchar sin descanso por la libertad de los presos políticos y sindicales, en elevar y redoblar esta lucha convirtiéndola en una grande y amplia acción popular a lo largo del país; consiste en exigir con mayor fuerza la derogación del delito de "disolución social", reclamar el cese del terror y los asesinatos en el campo, defender con todas las fuerzas la vigencia de las libertades constitucionales y los derechos democráticos ${ }^{36}$

De la misma manera se empieza a fraguar una consideración distinta sobre la Revolución Mexicana, expresión que aparecerá cada vez menos en el vocabulario comunista. No había ya tal horizonte, sino la necesidad de pensar otro. Enrique Semo, con su seudónimo, afirmaba:

Nada ha contribuido tanto a desenmascarar la mentira que encierra la demagogia de la burguesía gobernante, como los grandiosos movimientos populares en los años 1958-1959. El pueblo demostró estar listo para dar un gran paso hacia adelante en el cumplimiento de las reivindicaciones que encierra la constitución. No pedía socialismo, pedía mejores salarios, libertad de asociación, reformas radicales en el campo. Fue a tocar la puerta de aquellos que se dicen sacerdotes y herederos únicos de la "Revolución Mexicana", los de la izquierda "Dentro de la constitución". Pero ellos le contestaron con las cárceles y las bayonetas, y el pueblo está aprendiendo una nueva verdad, la verdad de una revolución que lo lleve al poder. 37

Sin embargo, de todos estos momentos, es el XIV Congreso en sus elaboraciones finales en donde cristaliza el proceso antes descrito. Ahí se finca finalmente la ruptura del comunismo mexicano con la Revolución Mexicana. Arnoldo Martínez Verdugo había lanzado críticas que señalaban a ideólogos "marxistas" de la Revolución Mexicana como Vicente Lombardo Toledano, cuando en el informe al congreso señalaba: "Muchos seudo marxistas o burgueses disfrazados, aceptan el marxismo en la medida en que este dirige su crítica con los

36 "Los comunistas y la situación política actual (Tesis para el XIV Congreso del PCM", Nueva Época, Año II, No. 5-6, enero-marzo de 1963, p. 39.

37 VILlanUEVA, A, "La revolución mexicana. Realidad y mito", Nueva Época, Año II, No. 9, diciembre de 1963, p. 55 . 
residuos del régimen feudal y el imperialismo, pero reniegan de él, en la medida en que enfoca sus dardos contra el capitalismo". ${ }^{8} \mathrm{Si}$ esto era apenas un llamado de agitación, lo que se fraguaba era una caracterización en donde la "burguesía nacional" había perdido impulso. No era ella más la encargada de desarrollar el progreso económico o la reforma agraria. Políticamente, se avanzaba a determinar de otra forma las necesidades de los sectores sociales.

Las resoluciones del XIV Congreso fueron finalmente publicadas en el número 12 de Nueva Época, cuya edición estuvo por entero dedicada a las distintas directivas que emanaban a partir del acto partidario. Destacamos la nomenclatura que señalaba la nueva revolución a la que aspiraban los comunistas, titulada, "Revolución democrática de liberación nacional”. Sus características programáticas eran claras: la eliminación de los monopolios, la realización de una "reforma agraria radical" que eliminara el latifundio y la gran propiedad capitalista de la tierra. Su eje articulador era la negativa de considerar a la "burguesía nacional" como un agente político, aunque reconocía a sectores de ella en confrontación con los gobiernos. De igual manera, se aducía que los gobiernos mexicanos, después de los años cuarenta, habían abierto la puerta al capital trasnacional. El gobierno al que aspiraban los comunistas con su programa daba un lugar central a los obreros y campesinos, así como destacaban la necesidad de la igualdad con la mujer respecto al trabajo. De la misma forma, hablaban de los indígenas, a los que dedicaban una significativa parte tanto en términos de cultura y educación.

Es el apartado V del Programa resultado de XIV Congreso en donde, quizá, se exponga de manera más clara el relevo de sentido que comenzaba a prefigurar la nueva política comunista. Titulado, "Por un gobierno democrático de liberación nacional” exponía los puntos de la democratización del Estado y del gobierno que los comunistas buscaban. Ello implicaba la reducción del mandato presidencial de 6 a 4 años, la eliminación de la cámara de los Senadores, la revocabilidad del mandato, la necesidad de que los encargados de los órganos del Estado fuesen

${ }_{38}$ MARTÍNEZ, Arnoldo, "Informe del Comité Central del Partido Comunista Mexicano al XIV Congreso Nacional Ordinario", Nueva Época, Año III, No. 10, septiembre de 1964, p. 24. 
electos democráticamente, la transformación del sistema de seguridad. Dice este apartado: "Los ciudadanos tendrán garantizados sus derechos electorales. En todos los casos, los electores tendrán derecho a revocar el mandato de quienes hayan sido electos para los puestos de representación popular." 39

Para resumir, el PCM en su XIV Congreso esboza una nueva concepción política. Ella fue resultado de varias confluencias, tanto electorales, como extra electorales. En su corazón se instaló retomar la reforma agraria que debía ser "radical", de la misma forma, plantearon conquistar la democracia, tanto sindical como electoral. Con tropiezos, el PCM se distanció del marxismo al estilo Lombardo Toledano que planteaba alianzas con la "burguesía nacional", al tiempo que entraba en un franco debate por la caracterización del capitalismo mexicano. Todo ello tuvo consecuencias importantes que hemos señalado en la última parte. El paso fuerza se avanzó en disolver la tutela con respecto a la ideología de la Revolución Mexicana, para llegar al punto nodal: la revolución a la que aspiraban los comunistas no pasaba por el camino de aquella. El camino al que conducía dicha ideología era el de la represión al sindicalismo -como en el periodo 58-59-, la muerte de los dirigentes campesinos - como la de Rubén Jaramillo- y el fraude electoral que negaba, en los hechos, los derechos más básicos. El camino comenzaba a trazarse con novedades y sólo al final de la década se mostraría la importancia de todos estos avances.

\section{Conclusiones}

El texto citado de Semo muestra la mayor ruptura del comunismo con la Revolución Mexicana en términos intelectuales. El PCM en su XIV Congreso dio, por su parte, los pasos necesarios para cristalizar la ruptura con la ideología de la Revolución Mexicana y, por lo tanto, la ruptura con toda dependencia programática. En términos prácticos, ello significó una doble ruptura. En el terreno económico el PC localizaba contradicciones al seno de la burguesía, pero no las consideraba ya un eje articulador de su política, ello los obligó a replantearse la

39 "Programa del Partido Comunista Mexicano: hacia una revolución democrática de liberación nacional”, Nueva Época, Año XII, No. 12, p. 54. 
concepción del capitalismo, eliminando toda noción de "feudalismo". En términos políticos, la ruptura fue más fuerte, pues se planteó, de manera clara y sin ambigüedades, la necesidad de disputar el corazón del régimen autoritario implantado desde la "Revolución hecha gobierno": el problema de la democracia.

En los años sesenta, esta centralidad de la democracia empieza a ganar terreno. Faltarán algunos cuantos años y sucesos muy importantes, como el movimiento estudiantil de 1968, para que la cuestión de la democracia se convierta en la bandera de la izquierda mexicana. Señalamos a través de la revista Nueva Época, un primer momento en donde esto se expresó, en un periodo previo al movimiento estudiantil-popular que emergerá después. Los motivos por los cuales la cuestión democrática se convirtió en la clave de la política comunista están dados a partir de varios vectores: las derrotas de los años cincuenta, la capacidad de articulación con el movimiento campesino independiente y la entrada en escena de otros sectores a través de las experiencias del MLN, el FEP y la CCI.

Ha sido Barry Carr, uno de los más importantes estudiosos de la izquierda mexicana, quien ha detectado la renovación del comunismo en esta época. Sin embargo, Carr lo señala a partir del cambio de la dirección partidaria, ocurrida en el XIII Congreso en 1960. Aquel congreso, según relata el historiador norteamericano, realizado en la clandestinidad en un antiguo burdel, operó como el momento de cambio de la dirección comunista a favor de los "renovadores".40 Aunque todo ello es importante, su cristalización se mostrará de forma más clara a partir de lo que hemos relatado en este texto, la revista Nueva Época fue el canal primero de expresión.

La renovación del comunismo mexicano, acontecida con claridad en los años setenta con el advenimiento de la "reforma política" que abrió la puerta a la participación electoral legal y cuyo máximo momento fue la disolución del PCM y la alianza con otras fuerzas para la creación del Partido Socialista Unificado de México (PSUM), no se dio por generación espontánea, ni por los bríos de una

\footnotetext{
${ }^{40}$ CARR, Barry, La izquierda mexicana a través del siglo XX, México, Era, 1996, p.226.
} 
dirección renovada. Sus antecedentes deben buscarse en estos primeros años sesenta, en los que se fue tejiendo la trama de un modelo distinto a los que se consideraban inspiración, es decir el soviético y el cubano, más cercano a la forma en que se desarrolló la experiencia italiana, con un fuerte énfasis en la democracia. Los límites de esta década son evidentes, tanto en el plano teórico como en la articulación de una gramática de la política más allá de los cánones del movimiento comunista internacional, sin embargo, es palpable una disputa en torno a las coordenadas articuladoras de la época, es decir, una tensión en torno a las herencias y perspectivas de la Revolución Mexicana. Fue Nueva Época en donde los conflictos entre las certezas y los ánimos de renovación se expresaron, como un pequeño adelanto de lo que acontecería después.

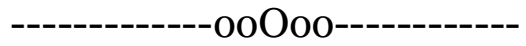

\section{Fuentes y Bibliografía}

\section{Archivos}

Centro de Estudios del Movimiento Obrero y Socialista (CEMOS)

\section{Libros}

CARR, Barry, La izquierda mexicana a través del siglo XX, México, Era, 1996.

CONDES LARA, Enrique, Atropellado amanecer: el comunismo en tiempos de la revolución mexicana, México, BUAP, 2015.

CONCHEIRO, Elvira, "Los comunistas mexicanos: entre la marginalidad y la vanguarida”, Elvira CONCHEIRO; Horacio CRESPO; Massimo MODONESI (Comp.), El comunismo: otras miradas desde América Latina, México, CEIICH, 2007.

CONCHEIRO, Elvira, "Gramsci en América Latina”, Massimo MODONESI (coord.), Horizontes gramscianos, México, FCPyS-UNAM, 2013.

DE LA FUENTE, Juan, Contra viento y marea: la pertinaz historia del movimiento campesino y las izquierdas, México, UACH, 2016.

GHIOLDI, Rodolfo, No puede haber revolución en la revolución, Buenos Aires, Anteo, 1967.

ILLADES, Carlos, La inteligencia rebelde, México, Océano, 2012.

PADILLA, Tanalís, Después de Zapata, México, AKAL, 2016.

REVUELTAS, José, Ensayo sobre un proletariado sin cabeza, México, Era, 1987. 


\section{Artículos en revistas.}

ALPEROVICH M.S, El papel de las masas populares en la Guerra por la Independencia de México”, Nueva Época, Año II, No. 9, diciembre de 1963.

BELENKI, A.B, “Objetivos y carácter de la intervención extranjera de 1861-1867”, Nueva Época, año 1, No. 2, abril de 1962.

CAMPA, Valentín, "El desarrollo económico de México y su caracterización”, Nueva Época, Año 1, No 4, octubre de 1962.

DANZÓS, Ramón, “Contra la imposición y el fraude electoral (discurso)” en Nueva Época, Año II, No. 9-10, diciembre de 1963.

GUEVARA, Ernesto, "La clase obrera cubana forja su partido”, Nueva Época, Año II, No. 8, junio-julio de 1963.

MALDONADO, Edelmiro, "El camino ultraizquierdiasta conduce a la derecha", Nueva Época, Año I, No. 2, abril de 1962.

MARTÍNEZ, Arnoldo, "Informe del Comité Central del Partido Comunista Mexicano al XIV Congreso Nacional Ordinario”, Nueva Época, Año III, No. 10, septiembre de 1964.

MARX, Carlos, "Entrevista al corresponsal el Chicago Tribune", Nueva Época, Año VII, No. 19, enero de 1969.

ROZHIN, V.P, “En torno a los elementos de la Dialéctica”, Nueva Época, Año 1, No. 1, febrero de 1961.

SÁNCHEZ, Baudelio, "Un portavoz de los comunistas mexicanos”, Nueva Época, Año 1, no. 4, octubre de 1962.

UNZUETA, Gerardo, "El MNL, una perspectiva para las luchas del pueblo”, Nueva Época, Año I, No. 1, febrero de 1961

UNZUETA, Gerardo, “Acerca de la caracterización económica de México”, Nueva Época, Año II, No. 7, abril-mayo de 1963.

UNZUETA, Gerardo, “Un fraude a la revolución (respuesta a Regis Debray”, Nueva Época, Año V, No 17, agosto de 1967.

TIRADO, Tirado, "El problema checoslovaco y la posición de principio del PCM", Nueva Época, Año VII, No. 19, enero de 1969.

VILLANUEVA, A, “10 artículos inéditos de Engels”, Nueva Época, Año 1, No. 3, agosto de 1962.

VILLANUEVA, A, "La revolución mexicana. Realidad y mito”, Nueva Época, Año II, No. 9, diciembre de 1963.

VILLANUEVA, A. "Las tareas de los intelectuales comunistas", Nueva Época, Año III, No. 11, mayo-junio de 1965.

VILLANUEVA, A, "El método marxista en el estudio del desarrollo económico de México", Nueva Época, Año II, No. 7, abril-mayo de 1963. 
"Lenin y el movimiento de liberación en las colonias", Nueva Época, Año II, No. 7, abril-mayo de 1963.

"Los comunistas y la situación política actual”, Nueva Época, Año II, No. 5-6, enero-marzo de 1963.

"Programa del Partido Comunista Mexicano (Proyecto)", Nueva Época, Año I, No 3, agosto de 1962, p. 19.

"Los comunistas y la situación política actual”, Nueva Época, Año II, No. 5-6, enero-marzo de 1963.

"Programa del Partido Comunista Mexicano (Proyecto)", Nueva Época, Año I, agosto de 1962, No. 3, p. 21.

"Los comunistas y la situación política actual (Tesis para el XIV Congreso del PCM", Nueva Época, Año II, No. 5-6, enero-marzo de 1963.

"Programa del Partido Comunista Mexicano: hacia una revolución democrática de liberación nacional”, Nueva Época, Año XII, No. 12. 